\title{
Consolidation and conversion of carbon powders into TiC by Reactive Chemical Vapour Infiltration
}

\author{
Olivier LEDAIN, Sylvain JACQUES, Laurence MAILLÉ \\ LCTS, CNRS, University of Bordeaux, Herakles-Safran, CEA, \\ 3 allee de la Boetie, F-33600, Pessac, France
}

\begin{abstract}
Ceramic samples were prepared using a hybrid process in which the ceramic powder route was combined with Reactive Chemical Vapour Infiltration, a new gas phase route. In this technique, a carbide growth occurs from the conversion of a carbonbearing powder and slows down with increase in carbide thickness due to solid-state diffusion limitation. This self-limitation is expected to allow a self-regulation of the growth between the interior and the surface of the sample and thus a better homogeneity. The chosen carbide was TiC obtained by reacting $\mathrm{H}_{2}$ and $\mathrm{TiCl}_{4}$ with a carbon powder introduced by slurry impregnation in felts. At $950^{\circ} \mathrm{C}$, the carbide infiltration is homogeneous with depth but the powder is not consolidated, while at $1050^{\circ} \mathrm{C}$ the better conversion rate of carbon into carbide allows the consolidation but the infiltration is limited to only about $250 \mu \mathrm{m}$. The consolidation depth can be improved with time-temperature steps between both temperatures.
\end{abstract}

\section{Keywords}

carbide; RCVI; hybrid process; powder consolidation; self-limitation

\section{Introduction}

Among the different methods used to fabricate ceramic matrix composites (CMCs), chemical vapour infiltration (CVI) allows carbide-based matrix to be obtained at moderate temperatures $\left(900-1100^{\circ} \mathrm{C}\right)$ with high purity and without shrinkage in woven fibre preforms of different shapes and sizes [1]. However, CVI is a slow and so a time consuming technique and the final CMCs display significant residual porosity. The matrices comprise thus macropores whose shapes and singularities cause stress concentrations responsible for early crack initiations during mechanical loading [2].

The ceramic powder route, for its part, allows the formation of the ceramic matrix inside the fibre preform by slurry impregnation [1] [3] [4]. This method is fast and low cost and, unlike CVI, avoids the formation of large pores at yarn intersections and between the plies. But after impregnation, the green powder parts have to be consolidated by hot pressing and sintering. The high temperature and mechanical pressure required for carbide sintering can lead to severe fibre degradation. Because of the shrinkage that occurs during the sintering, this method is limited to the 
preparation of unidirectional CMCs. Furthermore, the sintering additives can affect the final properties of the material.

The use of a hybrid process in which the slurry impregnation is followed by the gas phase route would overcome the limitations of each route used separately. However, a submicrometer powder compact is difficult to infiltrate by conventional CVI in large enough thickness due to a clogging effect. The gaseous precursor infiltrates in the fine porosity of the powder with difficulty. The carbide growth rate is lower at the interior of the powder than at the surface. This case is illustrated in Fig. 1. Because of the gaseous reactive species depletion within the powder, a pronounced deposition gradient is established around the particles and finally the seal-coating of the powder surface prevents further in depth infiltration.

In this way, Fig. 2 shows a carbon powder compact after four hours of SiC infiltration by conventional CVI carried out in our laboratory. Despite the use of very low pressure $(5 \mathrm{kPa})$ and temperature $\left(800^{\circ} \mathrm{C}\right)$ conditions such as to allow low growth rate for maximum infiltration, the depth of $\mathrm{SiC}$ infiltration beneath the surface of the sample is only about $20 \mu \mathrm{m}$. A seal-coating is observed at the sample surface evidencing that the entrance of the material is closed and that deeper infiltration is not possible. Itoh et al. could overcome this difficulty by using pulsed CVI instead of conventional CVI [5]. They could prepare in their laboratory CMCs from fibre preforms partly filled with $\mathrm{SiC}$ fine powder and then infiltrated with silicon carbide by pulsed $\mathrm{CVI}$ at a temperature below $900^{\circ} \mathrm{C}$ and a total time per pulse of only 1.1-2.0 s. However, the pulsed method is not suited to CMC manufacture on a large scale because the periodic gas evacuation in a few seconds of large industrial CVI reactors does not seem feasible.

The aim of this study is to develop a hybrid process that combines the advantage of slurry impregnation with a new gas phase route called reactive $\mathrm{CVI}(\mathrm{RCVI})$. RCVI is similar to reactive chemical vapour deposition (RCVD) but transferred to the infiltration and consolidation of porous media. In RCVD, the MC carbide coating is obtained by reacting a carbon-bearing substrate with the gas, which carries only the $\mathrm{M}$ element (being $\mathrm{B}, \mathrm{Hf}, \mathrm{Ta}, \mathrm{Si}, \mathrm{Ti}$...) but not the $\mathrm{C}$ element like in classical CVD [6] [7] [8] [9] [10] [11]. Once the substrate surface in covered with a continuous film of carbide, the continuation of the growth involves carbon diffusion from the substrate to the surface through the growing carbide film. So the growth slows down when the carbide thickness increases due to the limitation of solid-state diffusion. The carbide growth involves the consumption and the conversion of the original substrate. When $\mathrm{RCVI}$ is applied to the infiltration of a porous carbon-bearing substrate like a powder compact, i.e. without carbon in the original gaseous phase introduced in the reactor, the same gradient phenomenon as in conventional CVI is observed at the beginning of the process due to gaseous precursor infiltration difficulty (Fig. 3.a). But, because the carbon solid-state diffusion is limited when the thickness of the carbide coating increases, the RCVI process is expected to be self-limiting with self-balancing growth rates between the interior and the surface of the powder (Fig. 3.b). Thus, a homogeneous infiltration and consolidation should be obtained within the whole material (Fig. 3.c). In this work, titanium carbide has been chosen to study this concept for the first time because a mixture of titanium tetrachloride and hydrogen reacts easily with carbon to form TiC by RCVD and because carbon can diffuse through this carbide that can be sub-stoichiometric [7] [10] [12]. 


\section{Experimental}

\subsection{Synthesis}

Study materials, mainly consisting of green powder compacts, were prepared from RVG-2000 ${ }^{\circledR}$ carbon felt with a thickness of $6 \mathrm{~mm}$ in which the powder was introduced by slurry impregnation. The advantage of using this felt is that it contains a small amount of carbon fibres (6-10\% in volume) compared to the fibre preforms commonly used for the reinforcement of actual CMCs. This allows the easy preparation of the samples and allows the study to be focused on the RCVI of large green powder areas that are free of fibres while having a local porosity similar to that obtained in actual green CMCs prepared by slurry route. A stable aqueous suspension with a concentration of $34 \mathrm{vol}$ \% of carbon powder (Luvomaxx $\mathrm{N} 991^{\circledR}$ carbon black, $\mathrm{d}_{50} \# 600 \mathrm{~nm}$ ) and with a wetting and dispersing additive (DisperBYK $181^{\circledR}$ ) was prepared. Then, the pieces of felt were impregnated under vacuum for one hour. The solvent was evaporated by heating at $100^{\circ} \mathrm{C}$ under vacuum for one hour. Two cycles of impregnation / evaporation were applied to enhance the filling in the porosity of the felt.

The reactor used for the RCVI experiments was the same CVD device as Jouanny et al. [13]. It was a silica tube with an inner diameter of $6 \mathrm{~cm}$. The silica tube was placed inside a conventional electrical resistive furnace. The green study materials were placed in the $\sim 10 \mathrm{~cm}$ long hot area of the reactor and heated at a temperature ranging from $950^{\circ} \mathrm{C}$ to $1050^{\circ} \mathrm{C}$. The $\mathrm{H}_{2} / \mathrm{TiCl}_{4}$ gaseous mixture was introduced in the reactor with a total pressure maintained at a constant value of $5 \mathrm{kPa}$, a total flow rate equal to $300 \mathrm{sccm}$ (standard $\mathrm{cm}^{3} \mathrm{~min}^{-1}$ ) and with a dilution ratio $\left[\mathrm{H}_{2}\right] /\left[\mathrm{TiCl}_{4}\right]$ equal to 3 . In the same experimental conditions, several study material samples were placed together in the reaction chamber. The influence of time on infiltration was studied by stopping regularly the experiment and removing a sample after a few hours.

\subsection{Characterization}

Porosity $\left(P_{\text {original }}\right)$ and pore size distribution of the green study materials were determined by mercury intrusion porosimetry (AutoPore IV, Micromeritics).

Crystalline phases present in the samples were determined by X-ray diffraction patterns obtained in a Bragg-Brentano configuration (D8 advance, Bruker). Polished cross sections of samples were observed by scanning electron microscopy (SEMQuanta 400 FEG V2 microscope) using a backscattered electron (BSE) detector and with an accelerating voltage fixed at $10 \mathrm{kV}$.

After RCVI of various durations, the local apparent volume fractions of grown TiC $\left(\tau_{T i C}\right)$, remaining carbon $\left(\tau_{C}\right)$ and porosity $(P)$ were determined at different depths in the sample by image analysis from the BSE-SEM images using a specially designed Matlab program. The used BSE-SEM images corresponded to an observed area of $15 \mu \mathrm{m}$ wide and $13 \mu \mathrm{m}$ high and were 1024 pixels wide by 884 pixels high. In a BSESEM image, the bright areas correspond to TiC which recognition is straightforward. The dark areas correspond to either residual carbon or porosity. The difficulty was to sort through the carbon particles of generally rather circular shape and surrounded by a layer of $\mathrm{TiC}$ and the pores of a more complex shape. The method to determine the various contents consisted in binarizing the image into pixels of either a black or a 
white colour using a threshold level between the bright and dark levels. The volume fraction of $\mathrm{TiC}$ was then the number of white pixels out of the total number of pixels in the image. The binary image underwent then a morphological closing through dilation followed by erosion of the white areas. This step was to remove blurred image areas, discontinuities in the TiC layers and thresholding artefacts. Each black area was then considered to be a carbon particle or a pore depending on a morphological criterion not reported here, but based on the roundness and the size. The contours of the sorted areas were drawn in blue for parts recognized as carbon and in red for parts recognized as pores in the original image in order to visually estimate the relevance of the results (Fig. 4). The volume fractions of carbon or pores were then proportional to the number of pixels of each kind of area. The given values result from the averages for different used dilation/erosion radii. Knowing the original porosity of the carbon study materials ( $P_{\text {original }}$ ), it was then possible to determine the apparent volume conversion rate between the volume of grown carbide and the volume of consumed carbon $\left(R_{V}\right)$ after RCVI versus the depth of infiltration according to equation (1).

$$
R_{v}=\frac{\tau_{T i C}}{1-P_{\text {original }}-\tau_{C}}
$$

The minimal value of $R_{V}$ is obtained for nearly stoichiometric TiC and is the ratio between $\mathrm{TiC}$ molar volume and carbon molar volume. This minimal theoretical value is equal to about two [10].

A sample of the last series of RCVI experiments was observed by transmission electron microscopy (TEM, Philips, CM30ST, the $\mathrm{LaB}_{6}$ source operating at $300 \mathrm{kV}$ ). The thin slice $(\sim 100 \mu \mathrm{m}$ in thickness) was cut from the polished sample embedded in resin molding that was first observed by SEM. It was submitted to $\mathrm{Ar}^{+}$ion beam milling (JEOL, Ion Slicer, EM-09100IS) until the electron transparency of the region of interest is obtained. Selected area electron diffraction (SAED) patterns were recorded (selected-area diameter: $2 \mu \mathrm{m}$ ) as well as direct images in both bright field and TiC (111) dark field modes.

\section{Results and discussion}

After a thermal treatment at $1100^{\circ} \mathrm{C}$ under vacuum and before $\mathrm{RCVI}$, the compact powder of the study materials has a porosity $P_{\text {original }}=0.50( \pm 0.04)$ for an average pore size of $165 \mathrm{~nm}$ as measured by mercury porosimetry. It is worth noting that this result is in good accordance with the porosity $P=0.45-0.50$ locally measured by image analysis in the deepest areas of a sample infiltrated with a minimum of TiC by $\mathrm{RCVI}$. This value was used to calculate $R_{V}$ according to equation (1). The presence of $\mathrm{TiC}$ after RCVI is confirmed by the characteristic peaks of the carbide on the X-ray diffraction patterns (not shown here).

First, RCVI was studied at a temperature of $950^{\circ} \mathrm{C}$ for 4 hours to 36 hours. The volume fraction of $\mathrm{TiC} \tau_{\text {TiC }}$ and the depth of infiltration in the powder increase with time (Fig. 5). In the infiltrated area, $\tau_{\text {TiC }}$ tends to a plateau between 0.4 and 0.5 from 24 hours and up to a depth greater than $500 \mu \mathrm{m}$. The maximum value is reached more quickly near the surface than in depth. However, if there is no observed sealcoating as expected, the maximum of $\tau_{T i C}(0.52)$ is not located just at the end surface of the sample but at a depth of about $50 \mu \mathrm{m}$ (Fig. 6.a\&b). The reason is unclear, but 
this may be due to a good gas exchange by forced convection facilitated on the edge of the sample. The volume conversion rate $\left(R_{v}\right)$ decreases with depth and is below the minimal theoretical value of two. This means that a part of the consumed carbon is not converted into carbide but is lost in the form of gaseous by-product species which are evacuated out from the reactor. Such a behaviour has already been pointed out by Ledain et al. in the RCVD of TiC on pyrocarbon [10]. The carbon lost is responsible for the rather high porosity measured in the samples and the poor particle coalescence by TiC as observed by SEM (Fig. 6) despite the quantity of introduced carbide. It allows in return a homogeneous in-depth infiltration.

In Fig. 7, the apparent mean thicknesses of the carbide coatings around each particle are plotted with infiltration time for different depths. During the first period up to 8 hours, the travel speed of infiltration front is about $60 \mu \mathrm{m} / \mathrm{h}$. Near the whole material surface, the carbide coating thickness is already about $100 \mathrm{~nm}$ in these first hours whereas almost no coating is observed in depth. In the second period between 8 to 18 hours, the travel speed of infiltration front slows down and is about $20 \mu \mathrm{m} / \mathrm{h}$. The carbide coating suddenly appears in intermediate depths. In the third period between 18 to 36 hours, carbide appears at the depth of $500 \mu \mathrm{m}$. The travel speed of infiltration front further slows down to about $8 \mu \mathrm{m} / \mathrm{h}$. The thickness of the carbide layers increases gradually and slowly up to a maximum of about $130 \mathrm{~nm}$ everywhere in the sample up to this depth of $500 \mu \mathrm{m}$. Hence, the self-balancing of the growth rates, which allows the homogenization of carbide thickness with depth, is evidenced here.

A second round of RCVI experiments was carried out at a temperature of $1050^{\circ} \mathrm{C}$ for 4 hours to 24 hours. At this temperature, the volume fraction of TiC is higher and the porosity is lower than at $950^{\circ} \mathrm{C}$ near the surface. But there is nearly no improvement of the maximum of infiltration depth with time which remains limited to only about $250 \mu \mathrm{m}$ (Fig. 8). $\tau_{T i C}$ does not increase any more either beyond 16 hours. Like at $950^{\circ} \mathrm{C}$, seal-coating is not observed and the maximum of $\tau_{\text {TiC }}$ (here $\sim 0.8$ ) and density is not located just at the end surface of the sample; it is located here at a depth of about $10 \mu \mathrm{m}$ (Fig. 9.a). At this temperature, the volume conversion rate $R_{V}$ is higher than the minimum theoretical value of two. This volume increase during the carbon conversion without loss allows the particle coalescence by TiC as evidenced by the SEM observations where the material appears very dense, up to a depth of about $100 \mu \mathrm{m}$ (Fig. 9). At the same value of $\tau_{T i C} \approx 0.4$, the carbide phase coating the carbon particles forms a continuous matrix at $1050^{\circ} \mathrm{C}$ (Fig. 9.b\&c) whereas nearly independent core/shell-type particles are observed at $950^{\circ} \mathrm{C}$ with only a few simple points of contact (Fig. 6). It is possible that, under the combined effect of confinement and high temperature, the carbon containing gaseous by-products resulting from particle attack react in the porosity with titanium precursor to form additional TiC. The increase of the carbon volume conversion efficiency enhances the dense area formation near the sample surface that seals fresh gas access toward the core of the sample preventing the good infiltration of the powder. At $950^{\circ} \mathrm{C}$, the temperature would be too low to allow the reaction of these carbonaceous gaseous by-products which are then led straight out the sample.

A third series of RCVI experiments was carried out by raising in steps the temperature from $950^{\circ} \mathrm{C}$ to $1050^{\circ} \mathrm{C}$. The purpose was to combine the in-depth homogeneity of infiltration achieved at low temperature with the pore-filling and density obtained at high temperature. A first 16 -hours step at $950^{\circ} \mathrm{C}$ allowed the infiltration of TiC in the study materials up to a depth of $500 \mu \mathrm{m}$ with a maximum $\tau_{T i C}$ limited to $\sim 0.5$ near the surface (Fig. 10). This result is in accordance with the one 
previously obtained in the first series of experiments carried out at the constant temperature of $950^{\circ} \mathrm{C}$. The following temperature steps were then divided into a series of six hours in order to get an overview of the intermediate states of infiltration. At $1000^{\circ} \mathrm{C}$, an increase of both infiltration depth (with a travel speed of infiltration front of $\sim 8 \mu \mathrm{m} / \mathrm{h}$ ) and $\tau_{T i C}$ is observed. Finally, at $1050^{\circ} \mathrm{C}$ an increase of $\tau_{T i C}$ is still observed near the surface of the samples, at a depth of 25 to $100 \mu \mathrm{m}$. The SEM observations show that the final study material is well densified up to a depth of 200 $300 \mu \mathrm{m}$. The TiC matrix exhibits a good continuity with porosity as low as $3 \%$ in the densest area (Fig. 11.a) and 18\% $200 \mu \mathrm{m}$ beneath the surface (Fig. 11.b). At this depth, the use of a unique temperature of $950 \mathrm{C}$ results in a porosity higher than $30 \%$. In this area, the good pore-filling is in accordance with a volume conversion rate $R_{V} \approx 2.2$ close to, but greater than the minimal theoretical value, reflecting the efficient conversion rate of carbon into carbide.

A TEM observation of the sample at an estimated depth of around $150 \mu \mathrm{m}$ is presented Fig. 12. The former carbon particles have been transformed into polycrystalline carbide particles. Each carbide particle can be identified by its more or less circular contour surrounded by pores. When the diameter of the transformed particle is lower than $\sim 600 \mathrm{~nm}$, no carbon is observed in the core, evidencing a total conversion. But when the particle size is higher, carbon remains in the centre and a core/shell structure is observed as in the case at the top and lower left of Fig. 12.a. In that case, the thickness of the carbide coating (shell part) around the remaining carbon (core part) is around $300 \mathrm{~nm}$. The SAED pattern of the area is typical of polycrystalline titanium carbide (Fig. 12.b). A (002) carbon ring is hardly visible and they are no diffraction spots other than those of TiC, evidencing that there is no free titanium. A few carbide crystal grains are highlighted in dark field mode (Fig. 12.c) without noticing preferential orientation or particular aspect ratio. At this depth in this sample, a part of which has been made at $950^{\circ} \mathrm{C}$ for 16 hours, the carbide crystal grain size ranges from 20 to $200 \mathrm{~nm}$ with an average of $80 \mathrm{~nm}$. This average grain size corresponds to the coating thickness from which the carbide growth slows down dramatically after 3 hours of RCVI at this depth (Fig. 7). As long as the carbide coating thickness is lower than this average grain size, the carbide growth can be considered to occur from direct reaction between the gas phase and carbon; the gaseous molecules have direct access to the carbon substrate between the growing carbide grains. Beyond this thickness, the grain edges join together and further reaction is only possible through solid state diffusion. At $950^{\circ} \mathrm{C}$ the growth is stopped when the coating thickness reaches $130 \mathrm{~nm}$ (Fig. 7), i.e. hardly twice the average grain size, because of too difficult diffusion. As long as gaseous species can reach the sample area, a temperature rise up to $1050^{\circ} \mathrm{C}$ allows the reactivation of growth through solid state diffusion through carbide. The carbide coating can then be composed of a stack of several grains and reach up to $\sim 300 \mathrm{~nm}$ in thickness. According to Van Loo et al. who studied different $\mathrm{TiC}-\mathrm{Ti}, \mathrm{TiC}-\mathrm{C}$ and $\mathrm{TiC}_{1-\mathrm{y}}-\mathrm{TiC}_{1-\mathrm{z}}$ diffusion couples, carbon is the only diffusing component in TiC [14]. Consequently at the particle level, the carbide growth should be driven only by the outwards diffusion of carbon and not by the inwards diffusion of titanium. But, when a nonreciprocal mutual solid-state diffusion process through an interface of two materials takes place, "Kirkendall voids" are formed close to the interface that leads to the formation of hollow objects [15] [16]. Here, there is no evidence of hole or void in place of carbon in the centre of the particles and the particles are not hollow. The production of dense carbide particles means that titanium can diffuse inwards. The discrepancy with Van Loo et al.'s observations may result from a difference in the involved mechanism: 
grain boundary diffusion in very fine-grained carbide in the RCVI case that facilitates element mobility vs. bulk diffusion in coarse-grained carbide in the diffusion couple technique case. The junction between three particles can be observed in Fig. 12.d. The particle junction results in grain boundary formation in the manner of a sintering mechanism, but the material consolidation is limited by the remaining pores between particles.

$R_{V}$ and $\tau_{\text {TiC }}$ measured at each step and at different depths are reported in Fig. 13. Near the surface, $R_{V}$ nearly reaches its maximal value at the end of the first step, whereas at a greater depth it gradually increases with time. Thus, in depth, carbon increasingly tends to convert into carbide instead of being evacuated from the sample as in the case of RCVD or RCVI at a constant low temperature of $950^{\circ} \mathrm{C}\left(R_{V} \approx 1.4\right.$ between 150 and $300 \mu \mathrm{m}$ deep after $36 \mathrm{~h}$ ). Compared to RCVIs at a constant single temperature, whether at $950^{\circ} \mathrm{C}$ or $1050^{\circ} \mathrm{C}$, increasing in steps the temperature helps to improve the material densification up to a depth of $300 \mu \mathrm{m}$.

\section{Conclusion}

At a low temperature of $950^{\circ} \mathrm{C}, \mathrm{RCVI}$ in the carbon - titanium carbide system allows the infiltration of the powder up to a depth of $\sim 700 \mu \mathrm{m}$, while the infiltration of SiC by conventional CVI is limited to a depth of only $20 \mu \mathrm{m}$ in the same carbon powder at even lower temperature of $800^{\circ} \mathrm{C}$. The thickness of the TiC coating around the particles is homogeneous thanks to the self limiting process with a plateau of about $130 \mathrm{~nm}$. But the particle coalescence is poor and a part of the carbon is evacuated in the gaseous phase. This phenomenon, by limiting the swelling of the converted particles, allows the material to be homogenized with a gradual increase of the infiltration depth.

At a single high temperature of $1050^{\circ} \mathrm{C}$, the infiltration depth is limited to only about $250 \mu \mathrm{m}$. There is still no seal-coating at the end surface like in conventional CVI, but owing to too rapid growth and good volume conversion rate of carbon into carbide without carbon lost, a dense area is formed near the surface which limits the diffusion of the gaseous reactive species. There is no increase of the infiltration front depth with time.

With the use of time-temperature steps from $950^{\circ} \mathrm{C}$ to $1050^{\circ} \mathrm{C}$, the consolidation of the powder is improved up to a depth of $300 \mu \mathrm{m}$. However to fabricate several millimetres thick CMCs with this hybrid process, the RCVI method needs to be further improved. Optimization should include the increase in the first step at $950^{\circ} \mathrm{C}$ over 16 hours. A process modelling, considering the phenomena observed as a function of temperature and depth, would allow for that optimization. Finally, it would also be interesting to consider different chemical systems with other elements than carbon and titanium.

\section{Acknowledgements}

This work was supported by Herakles (Safran group) and the Atomic Energy Commission. 


\section{References}

[1] R. Naslain "Design, preparation and properties of non-oxide CMCs for application in engines and nuclear reactors: an overview" Composites Science and Technology, 64 (2004) 155-170 http://dx.doi.org/10.1016/S0266-3538(03)00230-6

[2] L. Guillaumat, J. Lamon "Probabilistic-statistical simulation of the non-linear mechanical behavior of a woven $\mathrm{SiC} / \mathrm{SiC}$ composite" Composites Science and Technology, 56 (1996) 803-808 http://dx.doi.org/10.1016/0266-3538(96)00024-3

[3] K. Nakano, A. Hiroyuki, K. Ogawa "Carbon fiber reinforced silicon carbide composites" In: Füller J, et al., editors. Proc. 4th. ECCM-Conference, 25-28 September 1990, Stuttgart. Barking (UK): Elsevier Science; (1990) 419-424.

[4] J.B. Veyret, P. Tambuyser, C. Olivier, E. Bullock, M.-H. Vidal-Sétif "Hi-Nicalon reinforced silicon nitride matrix composites" Journal of Materials Science, 32 (1997) 3457-3462 http://dx.doi.org/10.1023/A:1018680919057

[5] K. Itoh, M. Imuta, A. Sakai, J. Gotoh, K. Sugiyama "Pulsed chemical vapour infiltration of $\mathrm{SiC}$ to three-dimensional carbon fibre performs" Journal of Materials Science 27(1992) 6022-6028 http://dx.doi.org/10.1007/BF01133744

[6] T. Takahashi, K. Sugiyama, K. Tomita "The chemical vapour deposition of titanium carbide coatings on iron" Journal of the Electrochemical Society, 114 (1967) 1230-1235. http://dx.doi.org/10.1149/1.2426456

[7] C. Vincent, J. Dazord, H. Vincent, J. Bouix, L. Porte, "Effet des conditions expérimentales sur la CVD réactive de couches minces de TiC sur carbone", Journal of Crystal Growth, 96 (1989) 871-880 http://dx.doi.org/10.1016/00220248(89)90647-7

[8] J. Bouix, M.P. Berthet, F. Bosselet, R. Favre, M. Peronnet, J.C. Viala, C. Vincent, $\mathrm{H}$. Vincent, "Interface tailoring in carbon fibres reinforced metal matrix composites" Journal de Physique IV, 07 (C6) (1997) C6-191-C6-205 http://dx.doi.org/10.1051/jp4:1997616 https://hal.archives-ouvertes.fr/jpa-00255715

[9] J. Bouix, M.P. Berthet, F. Bosselet, R. Favre, M. Peronnet, O. Rapaud, J.C. Viala, C. Vincent, H. Vincent, "Physico-chemistry of interfaces in inorganicmatrix composites", Composites Science and Technology, 61 (2001) 355-362 http://dx.doi.org/10.1016/S0266-3538(00)00107-X

[10] O. Ledain, W. Woelffel, J. Roger, G. Vignoles, L. Maillé, S. Jacques "Reactive Chemical Vapour Deposition of Titanium Carbide from $\mathrm{H}_{2}-\mathrm{TiCl}_{4}$ Gas Mixture on Pyrocarbon: A Comprehensive Study", Physics Procedia, 46 (2013) 79-87 http://dx.doi.org/10.1016/i.phpro.2013.07.048

[11] N.I. Baklanova, T.M. Zima, A.I. Boronin, S.V. Kosheev, A.T. Titov, N.V. Isaeva, D.V. Graschenkov, S.S. Solntsev "Protective ceramic multilayer coatings for carbon fibers" Surface \& Coatings Technology, 201 (2006) 2313-2319 http://dx.doi.org/10.1016/j.surfcoat.2006.03.046

[12] F. J. J. van Loo, G. F. Bastin "On the diffusion of carbon in titanium carbide" Metallurgical Transactions A, 20 (1989), 403-411

http://dx.doi.org/10.1007/bf02653919

[13] I. Jouanny, S. Jacques, P. Weisbecker, C. Labrugère, M. Lahaye, L. Maillé, R. Pailler "Synthesis of $\mathrm{TiC}$ from porous carbon coating on $\mathrm{Si}-\mathrm{C}-\mathrm{O}$ (Nicalon) fibres by reactive chemical vapour deposition in pressure-pulsed mode or at atmospheric pressure" Journal of Materials Science, 45 (2010) 6747-6756 http://dx.doi.org/10.1007/s10853-010-4769-9

[14] F.J.J. Van Loo, W. Wakelkamp, G.F. Bastin, R. Metselaar "Diffusion of carbon in $\mathrm{TiC}_{1-y}$ and $\mathrm{ZrC}_{1-\mathrm{y}}$ " Solid State lonics, 32/33 (1989) 824-832 http://dx.doi.org/10.1016/0167-2738(89)90364-0 
[15] H.J. Fan, U. Gösele, M. Zacharias, "Formation of nanotubes and hollow nanoparticles based on Kirkendall and diffusion processes: a review" Small, 3 (2007) 1660-1671 http://dx.doi.org/10.1002/smll.200700382

[16] Geon Dae Moon, Sungwook Ko, Yuho Min, Jie Zeng, Younan Xiaa, Unyong Jeong "Chemical transformations of nanostructured materials" Nano Today, 6 (2011), 186-203 http://dx.doi.org/10.1016/j.nantod.2011.02.006 

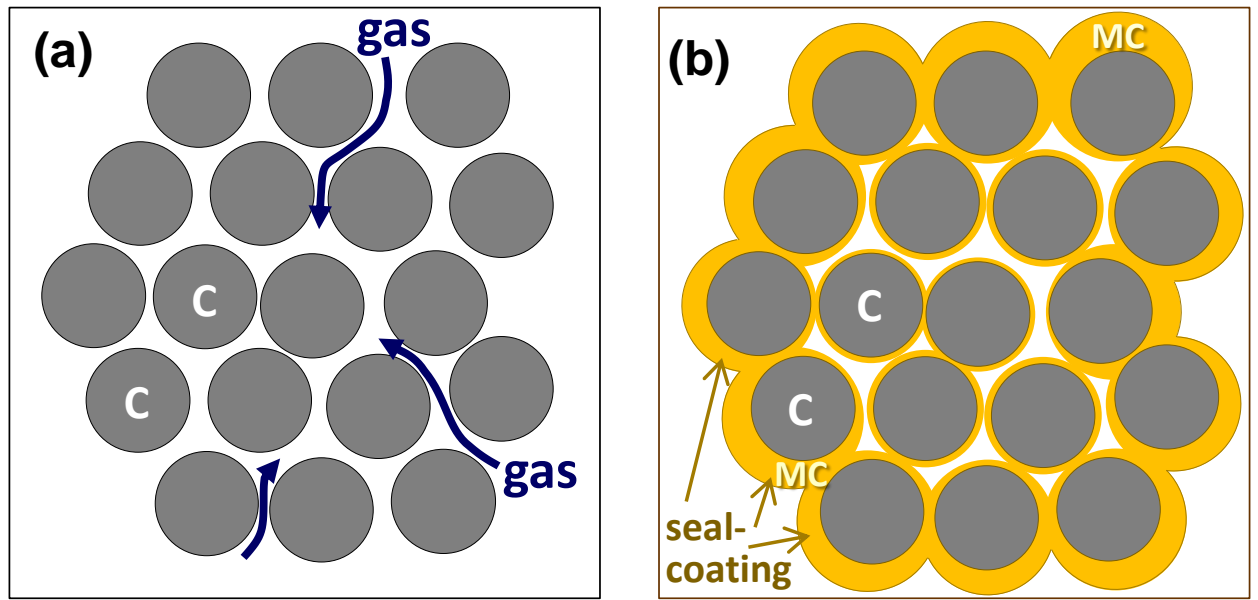

Fig.1: Schematic representation of the infiltration of a carbon powder compact with a carbide MC by conventional CVI. Initial powder (a) and final material (b).
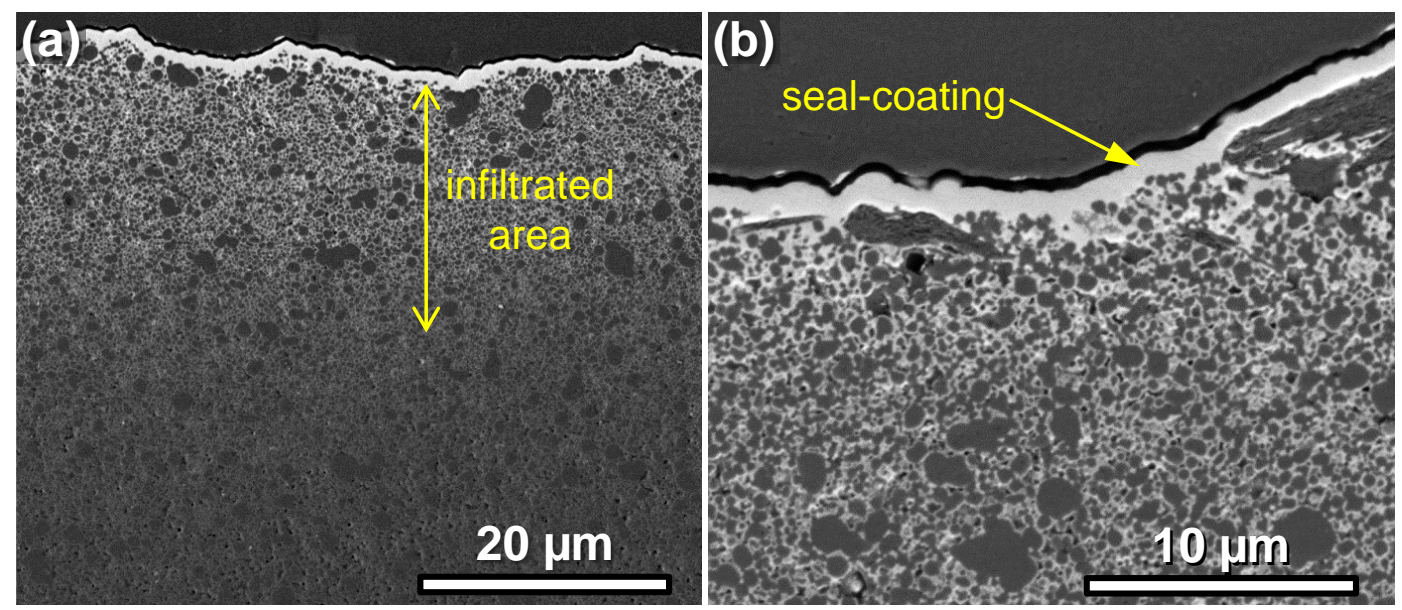

Fig.2: SEM observations of a polished cross-section of a carbon powder compact infiltrated with $\mathrm{SiC}$ by conventional CVI (surface on the top). Global view (a) and local view (b) of the surface.
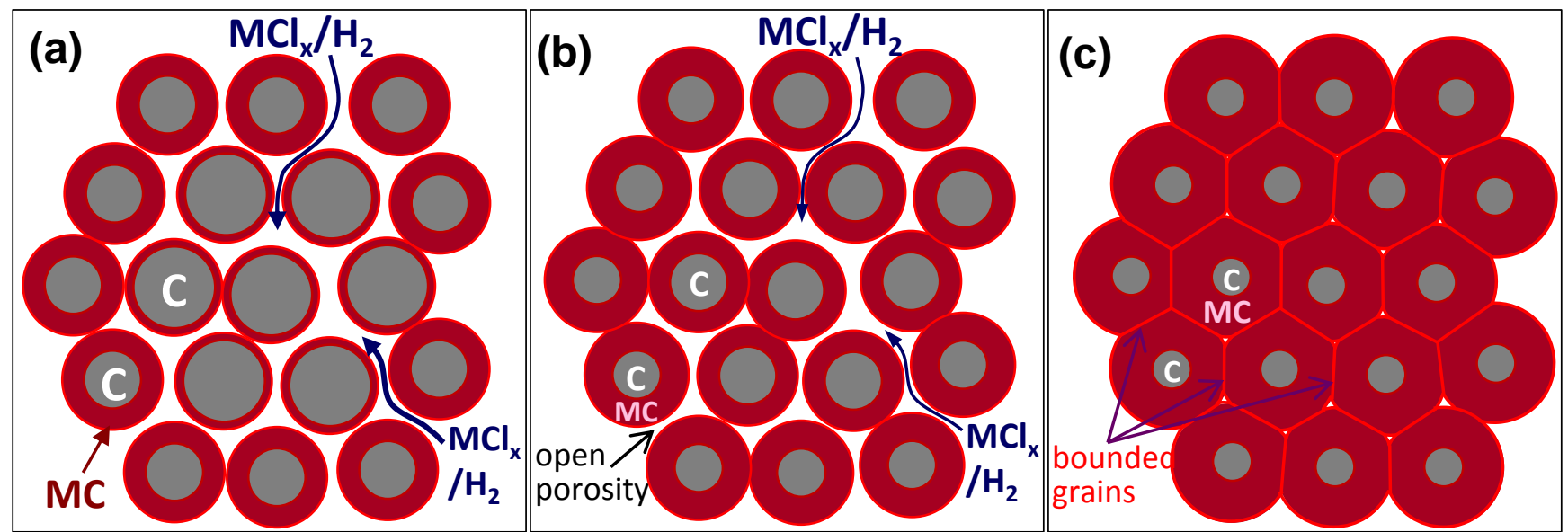

Fig.3: Schematic representation of the infiltration of a carbon powder compact and conversion into a carbide MC by RCVI. Beginning of the process (a), intermediate state (b) and final material (c). 


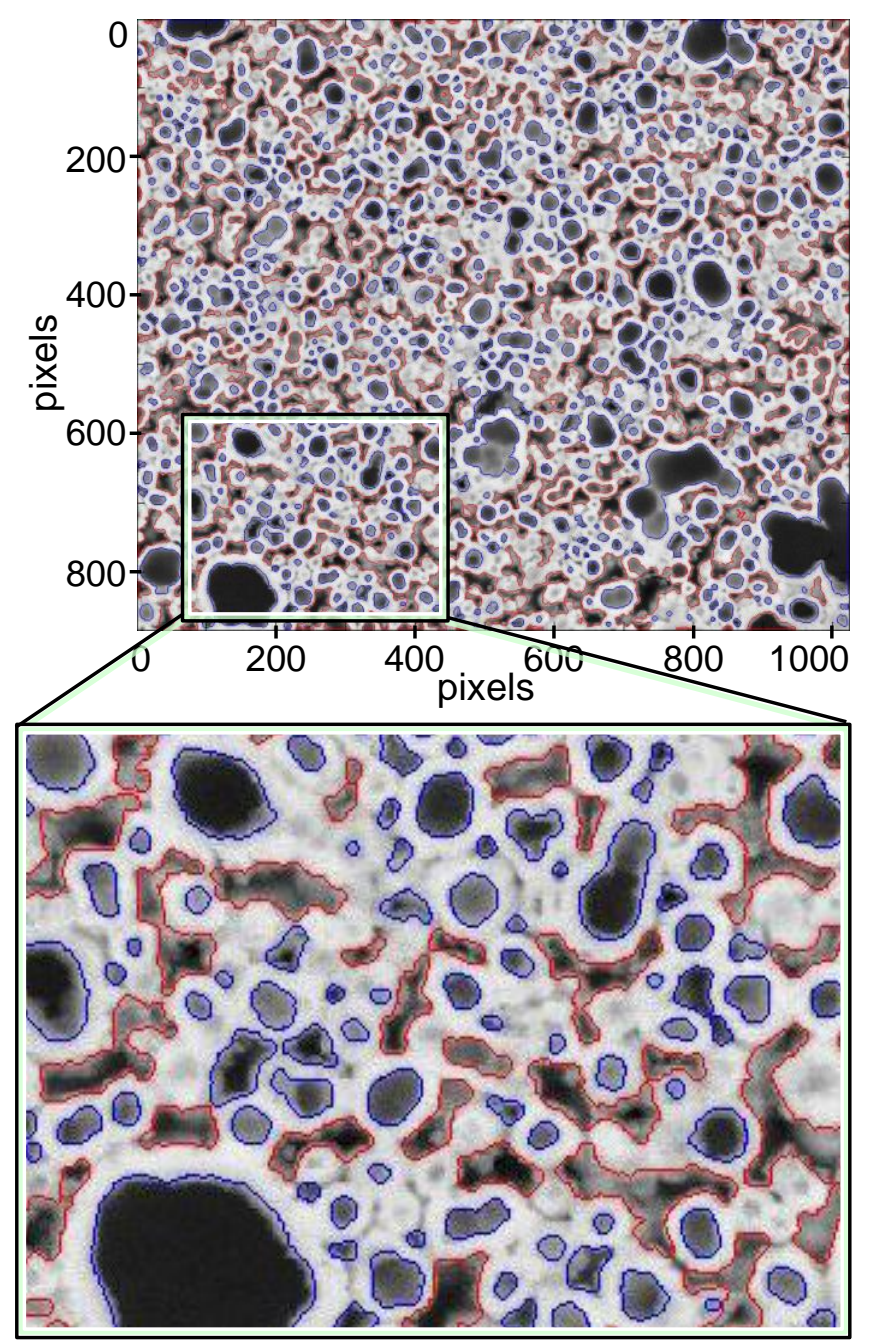

Fig.4: Image analysis of a study material observed by SEM at a depth of $50 \mu \mathrm{m}$ after $36 \mathrm{~h}$ of RCVI at $950^{\circ} \mathrm{C}$. Total width of the observed area equal to $15 \mu \mathrm{m}$. Contours of the areas recognized as carbon drawn in blue and in red for parts recognized as pores.

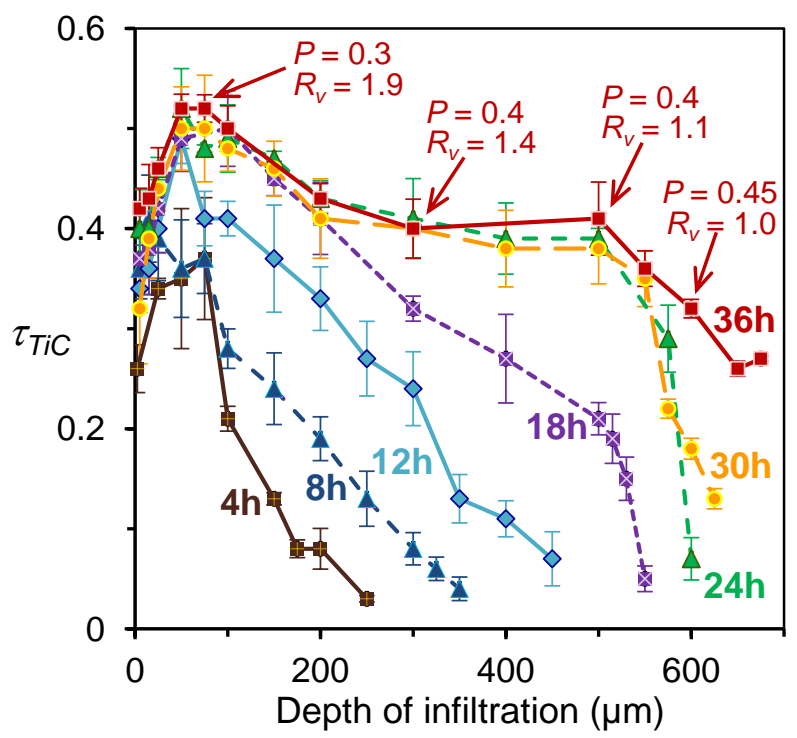

Fig.5: Apparent volume fraction of TiC $\tau_{T i C}$ vs. depth of infiltration in study materials after $\mathrm{RCVI}$ at $950^{\circ} \mathrm{C}$ for 4 hours to 36 hours. 

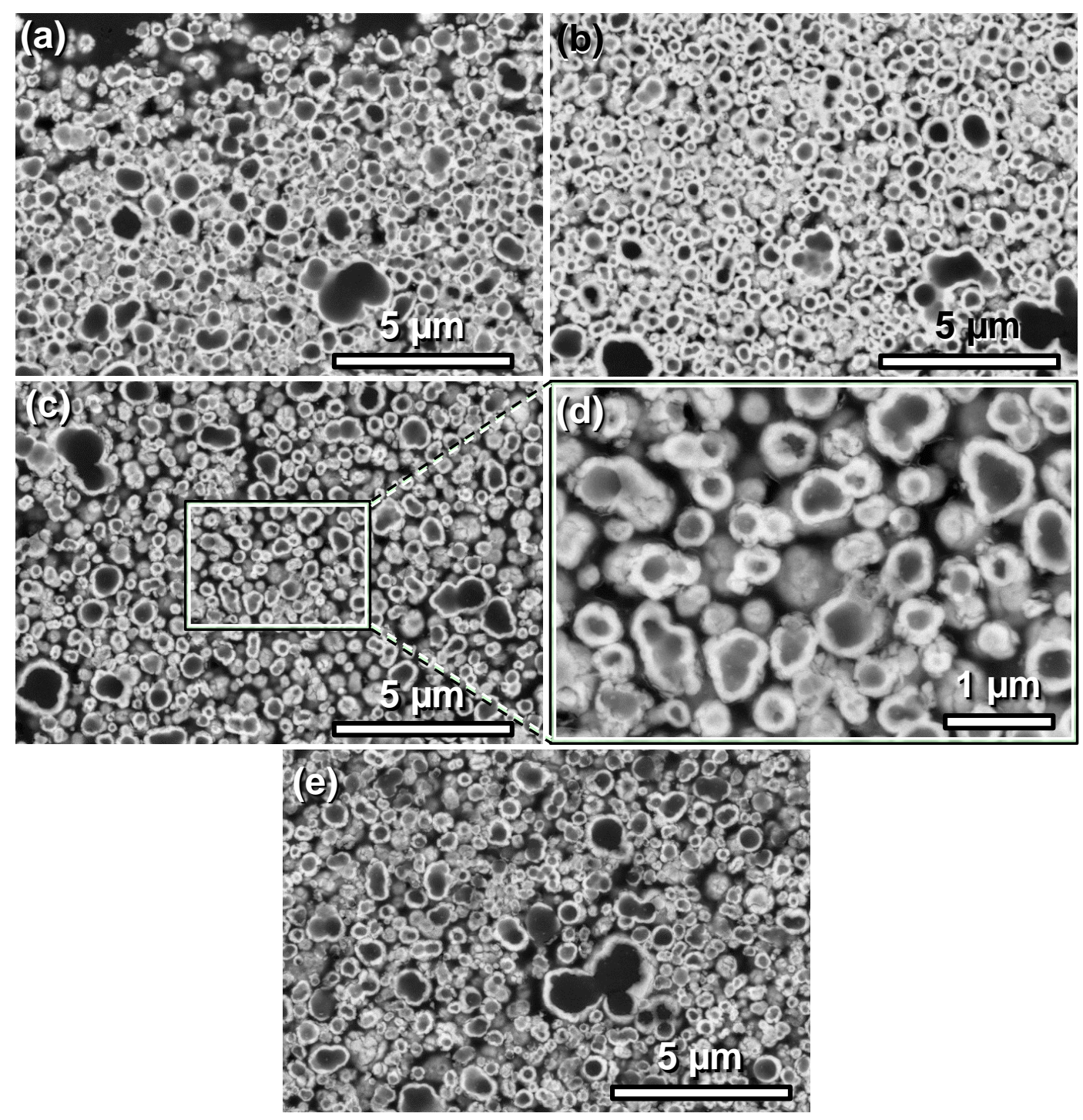

Fig.6: SEM observations of the study materials after RCVI at $950^{\circ} \mathrm{C}$ for 36 hours at the surface $\left(\tau_{T i C}=0.42\right.$, surface on top) (a), at a depth of $50 \mu \mathrm{m}\left(\tau_{T T C}=0.50, P\right.$ $=0.30)(\mathrm{b})$, at a depth of $300 \mu \mathrm{m}\left(\tau_{T i C}=0.40, P=0.40\right)(\mathrm{c})$, magnification of Fig. $\mathrm{c}$ (d), and at a depth of $600 \mu \mathrm{m}\left(\tau_{T i C}=0.35, P=0.45\right)(\mathrm{e})$. 


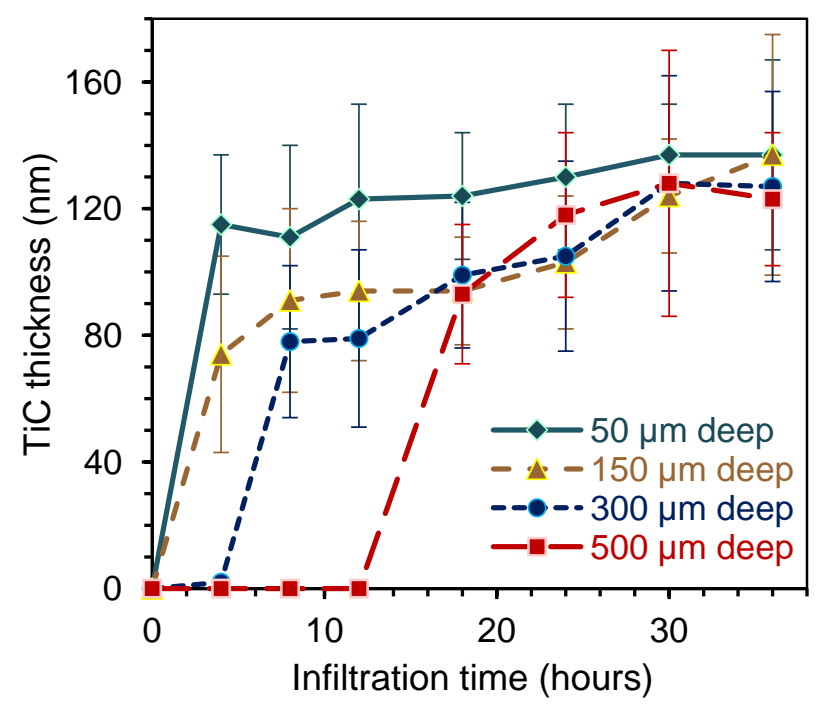

Fig.7: Apparent mean thickness of TiC around carbon particles vs. infiltration time at different depths in study materials after $\mathrm{RCVI}$ at $950^{\circ} \mathrm{C}$ every $4-6$ hours for 36 hours.

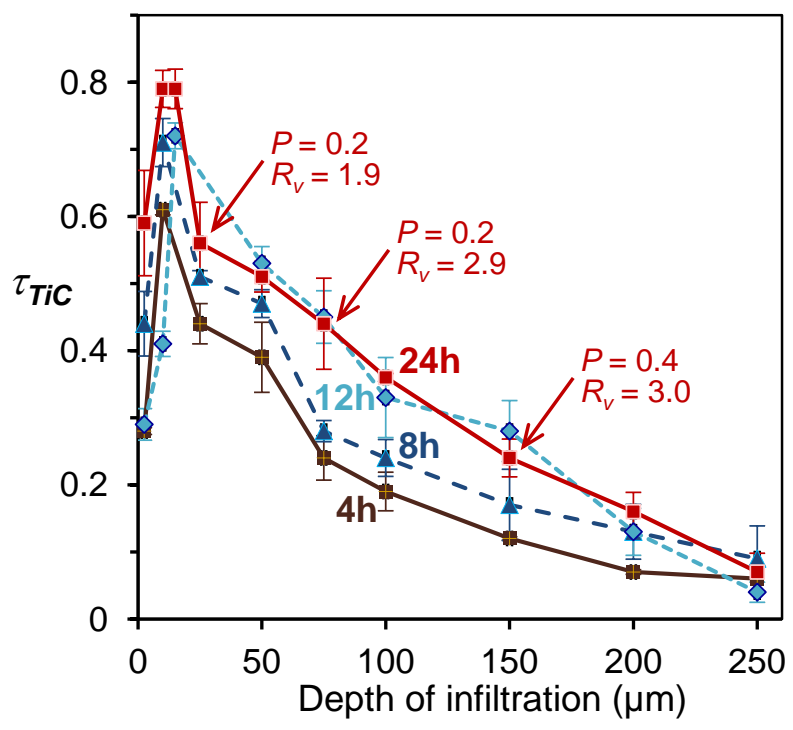

Fig.8: Apparent volume fraction of TiC $\tau_{T i C}$ vs. depth of infiltration in study materials after $\mathrm{RCVI}$ at $1050^{\circ} \mathrm{C}$ for 4 hours to 36 hours. 

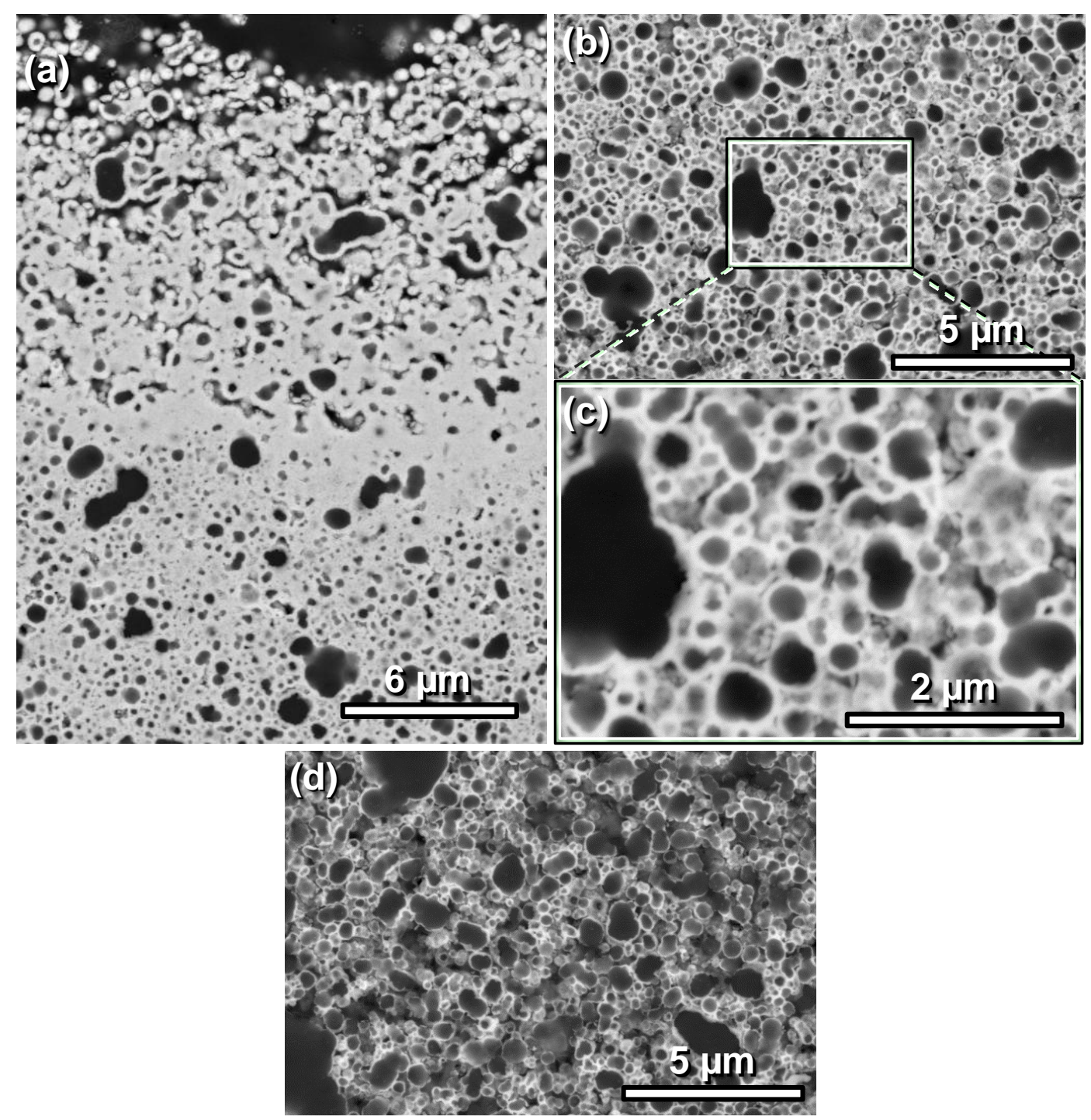

Fig.9: SEM observations of the study materials after RCVI at $1050^{\circ} \mathrm{C}$ for 24 hours at the surface (surface on top) (a), at a depth of $75 \mu \mathrm{m}$ (b), magnification of Fig. b (c), and at a depth of $150 \mu \mathrm{m}(\mathrm{d})$. 


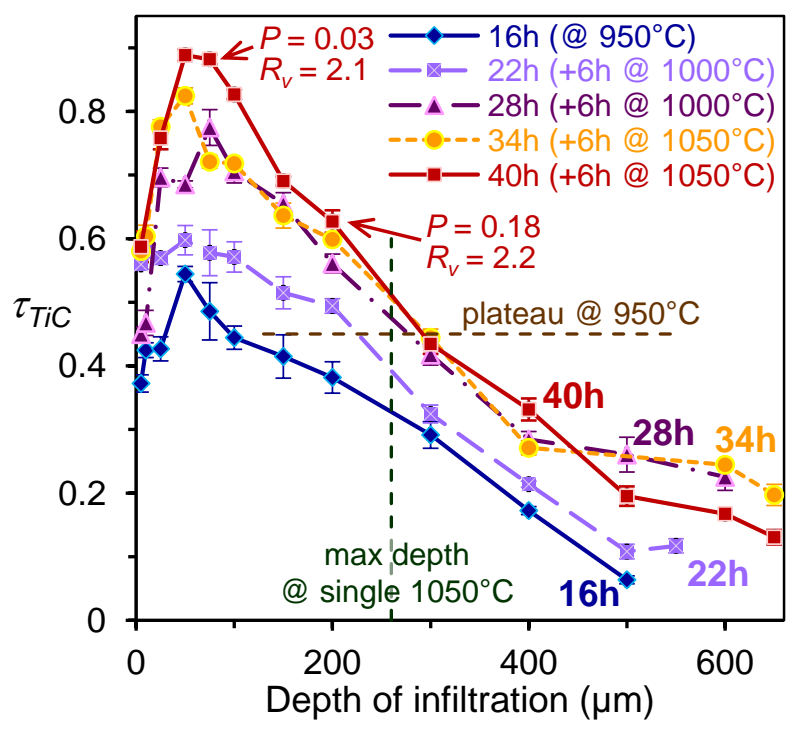

Fig.10: Apparent volume fraction of TiC $\tau_{T i C}$ vs. depth of infiltration in study materials after $\mathrm{RCVI}$ at temperature raising in steps from $950^{\circ} \mathrm{C}$ to $1050^{\circ} \mathrm{C}$ for total of 40 hours.
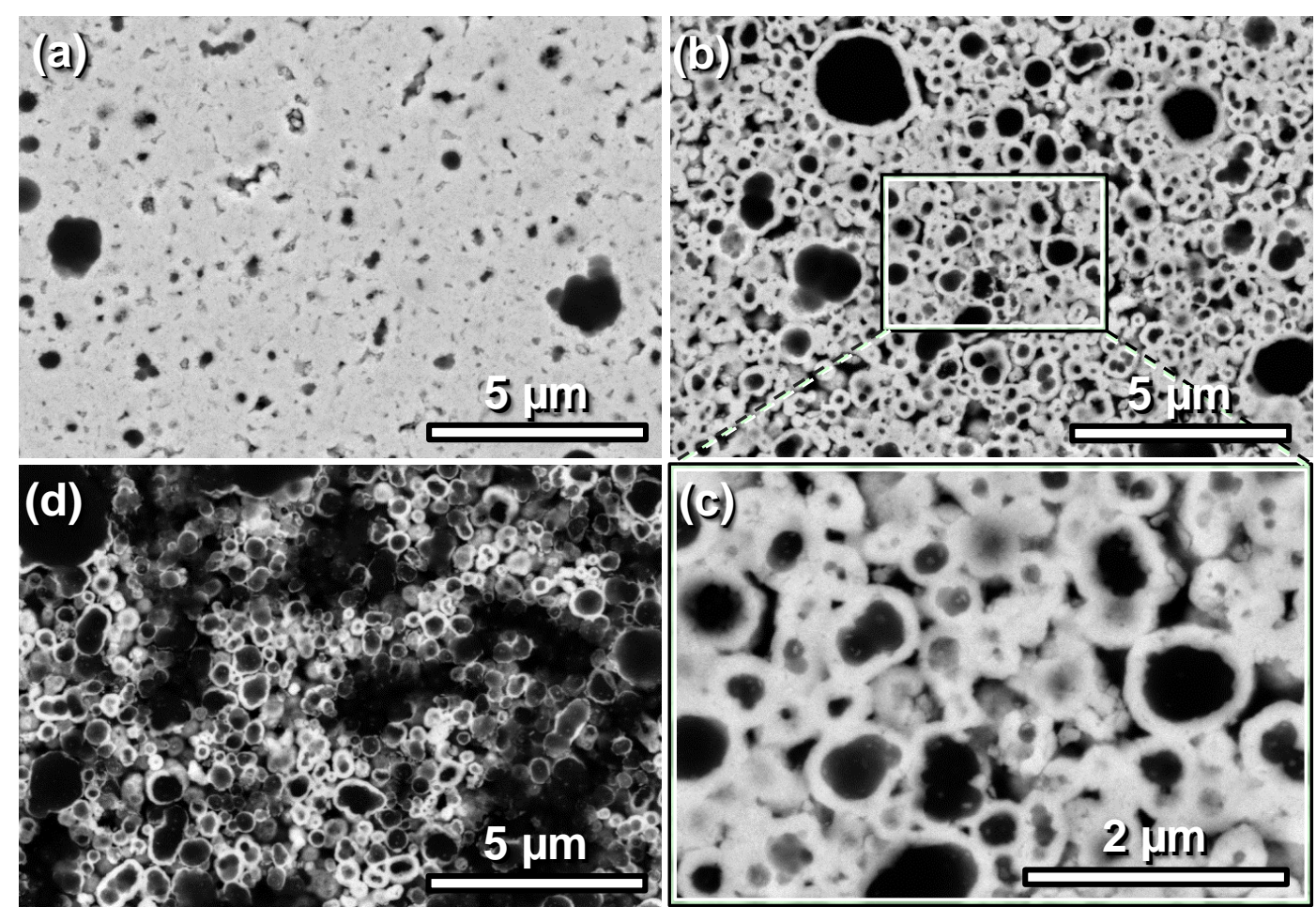

Fig.11: SEM observations of the study materials after RCVI carried out by raising in steps the temperature from $950^{\circ} \mathrm{C}$ to $1050^{\circ} \mathrm{C}$ for a total of 40 hours at a depth of $75 \mu \mathrm{m}(P=0.03)(\mathrm{a})$, at a depth of $200 \mu \mathrm{m}(P=0.18)(\mathrm{b})$, magnification of Fig. $\mathrm{b}$ (c), and at a depth of $500 \mu \mathrm{m}$ (d). 


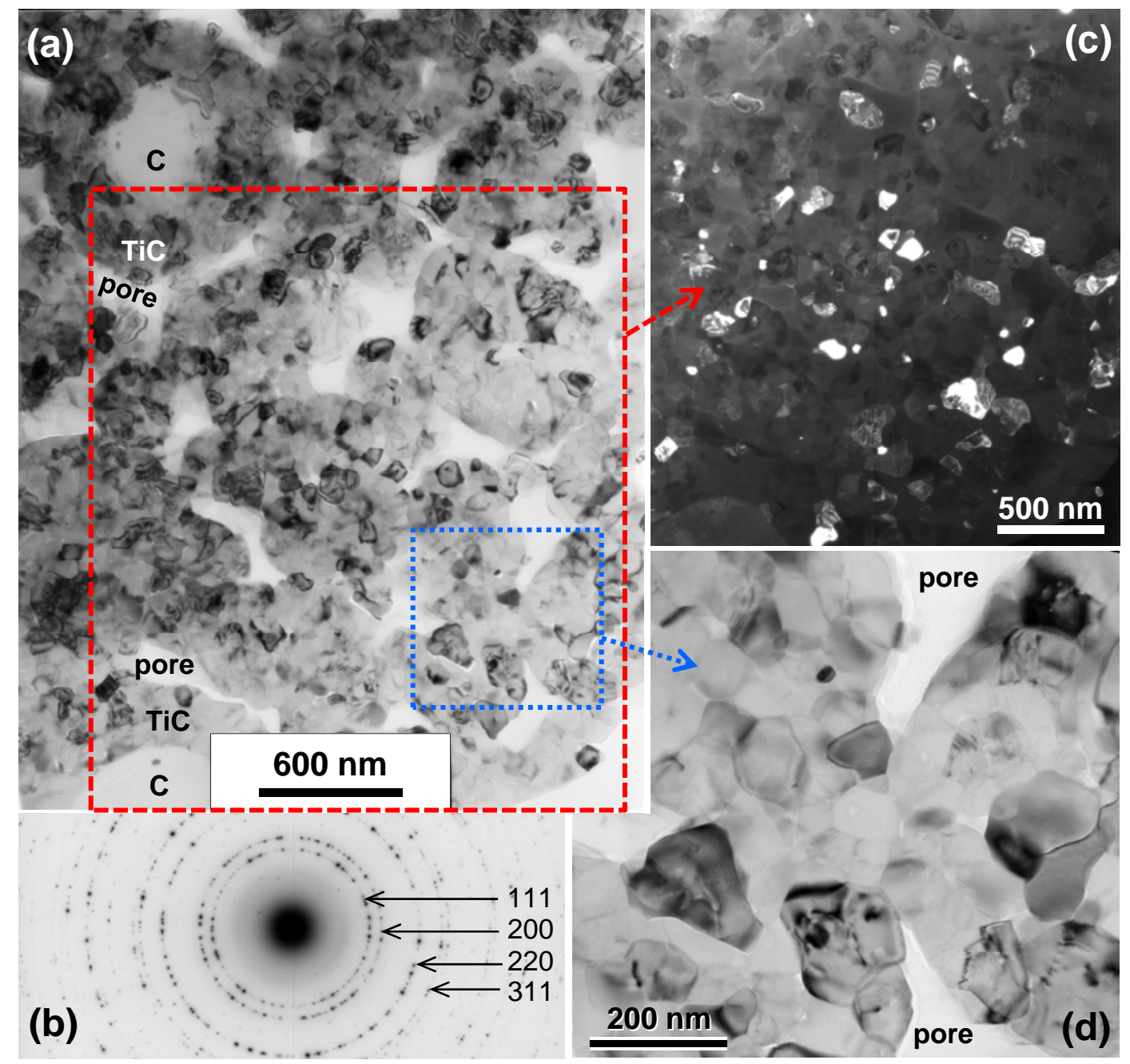

Fig.12: TEM observations of the study material after RCVI carried out by raising in steps the temperature from $950^{\circ} \mathrm{C}$ to $1050^{\circ} \mathrm{C}$ for a total of 40 hours at a depth of $\sim 150 \mu \mathrm{m}$ in bright field mode (a), SAED (b), dark field mode (c), and bright field mode at higher magnification $(\mathrm{d})$.

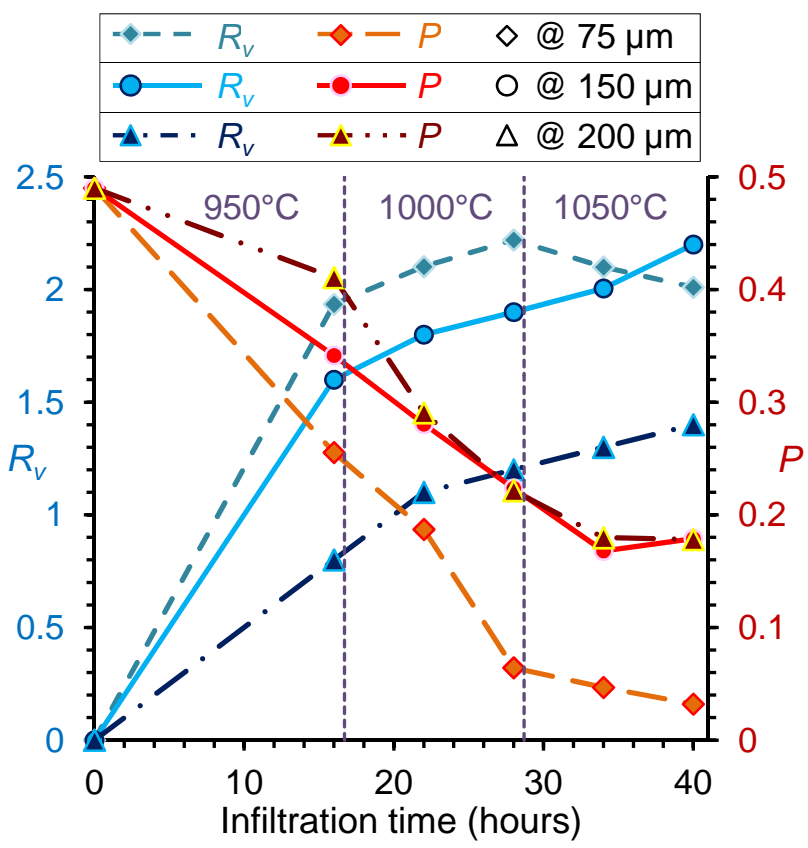

Fig.13: Apparent volume conversion rate $R_{v}$ and porosity $P$ vs. infiltration time at depths of $75 \mu \mathrm{m}, 150 \mu \mathrm{m}$ and $200 \mu \mathrm{m}$ in study materials after RCVI at temperature raising in steps from $950^{\circ} \mathrm{C}$ to $1050^{\circ} \mathrm{C}$. 